\title{
How Can we Relate Pulse Rate with Choice of taking Swimming as a Hobby?
}

\author{
Muhammad Imran Qadir and Tooba Komal* \\ Institute of Molecular Biology and Biotechnology, Pakistan
}

*Corresponding author: Tooba Komal, Institute of Molecular Biology and Biotechnology, Bahauddin Zakaria University Multan, Pakistan

\section{ARTICLE INFO}

Received: 慧 February 06, 2019

Published: 幽 February 15, 2019

Citation: Muhammad Imran Qadir ,Tooba Komal. How Can we Relate Pulse Rate with Choice of taking Swimming as a Hobby?. Biomed J Sci \& Tech Res 14(4)-2019. BJSTR. MS.ID.002583.
ABSTRACT

Objective: Objective of the present study was to co-relate pulse rate with choice of people taking swimming as a hobby. A total of 200 subjects participated in the present study. They were given a questionnaire asking subjects their pulse rate in two options, YES and NO that whether they have swimming as a hobby or not. Pulse rate was calculated by radial pulse method. First pointer and middle fingers were placed on the inside of the opposite wrist below the thumb. Thumb was not used to check the pulse, as the artery in thumb could make it harder to count precisely. Once their pulse was felt, no. of beats was counted in 15 seconds. This number was multiplied by 4 to get the heart rate. It was concluded that choice of taking swimming as a hobby do not relate with the pulse rate as our results are non-significant.

Keywords: Pulse rate; Swimming; Average; Standard Deviation

\section{Introduction}

In the past, people relate their diseases with the pulse rate. When they got diseased, their physician checked their pulse by hand and according to the rate of pulse whether high or low, they predicted the disease type. This was a very common phenomena in the past but is not practiced in present because people are more educated and aware now. In some backward areas, it is still practicing because of lack of education and awareness [1-5].

\section{Pulse Rate}

Pulse is the heart rate and in other words, it is the no. of times heart beats in one minute. Pulse rate differ from individual to individual. It has a slower rate when at rest and a higher rate when doing exercise. In children from age 6-100, normal pulse rate ranges between 70-100. In adults, its rate ranges from 60-100. We can calculate it easily on our own. Below the base of the thumb, place the tips of your index, middle and third fingers on the palm side of your other wrist. Press lightly with your fingers and feel the pulsing beneath your fingers. Move your fingers slightly up or down until you feel the blood pulsing. Use a watch or a clock and count the beats for 10 seconds. Multiply these no. of beats by six to get your pulse or heart rate per minute. If pulse rate is 0 , it means the person is dead. Pulse is related to cardiac diseases mostly. If you are feeling unhealthy, your doctor will first check your pulse rate and then proceed with the medication. You should check it often and if there is some disturbance with the pulse rate, u should go to your doctor [6-9].

\section{Swimming as a Hobby}

Swimming can be a healthy hobby and exercise. This is a good way for enjoyment and to increase your fitness. Swimming strengthens our muscles, relieves stress and improves or increases the stamina and fitness. It is also good to control the fat and cholesterol levels and for the blood pressure and its circulation. It can also be beneficial to our mind and soul. It boosts up our energy levels by refreshing our minds. Regular swimming can burn the fats. It can also be beneficial for pregnant women as it is healthy for them and for the people which are recovering from surgical treatments and medications. There are some artificial or public swimming pools in the city in which you are living in which can be used for your swimming sessions. So, swimming is one of the best hobby one can have and it is the best and low impact exercise which is beneficial in every aspect and at any age. 


\section{Materials and Methods}

A total of 200 subjects participated in the present study. They were given a questionnaire asking subjects their pulse rate. Pulse rate was calculated by radial pulse method. First pointer and middle fingers were placed on the inside of the opposite wrist below the thumb. Thumb was not used to check the pulse, as the artery in thumb could make it harder to count precisely. Once their pulse was felt, no. of beats was counted in 15 seconds. This number was multiplied by 4 to get the heart rate. For example, 20 beats in 15 seconds equals to a heart rate of 80 beats per minute (bpm). People who have swimming as a hobby wrote their pulse rate in YES portion and the subjects which do not have swimming as a hobby wrote their pulse rate in NO portion because we are relating pulse rate with choice of taking swimming as a hobby [10].

\section{Statistical Analysis}

Statistical analysis of the present study was performed by SAS. $\mathrm{t}$-Test was used to analyze the results.

\section{Results and Discussion}

P-value was set $>0.05 \%$ as significant. (Table 1) People who take swimming as a hobby have more pulse rate as compared to the pulse rate of people who do not. The average pulse rate of people who said YES is 81.32 with standard deviation of 10.32. The average pulse rate of people who answered NO is $79.20+10.67$. The p value of pulse rate who answered YES and NO was calculated as $0.27 \%$ which is non-significant as It is greater than $0.05 \%$.

Table 1: Pulse Rates.

\begin{tabular}{|c|c|}
\hline \multicolumn{2}{|c|}{ Pulse Rates } \\
\hline Answer & Average \pm St. Deviation \\
\hline Yes & $81.32 \pm 10.32$ \\
\hline No & $79.20 \pm 10.67$ \\
\hline
\end{tabular}

ISSN: 2574-1241

DOI: 10.26717.BJSTR.2019.14.002583

Tooba Komal. Biomed J Sci \& Tech Res

This work is licensed under Creative Commons Attribution 4.0 License

Submission Link: https://biomedres.us/submit-manuscript.php

\section{Conclusion}

It was concluded that choice of taking swimming as a hobby do not relate with the pulse rate as our results are non-significant.

\section{References}

1. Åstrand PO, Ryhming I (1954) A nomogram for calculation of aerobic capacity (physical fitness) from pulse rate during submaximal work. Journal of applied physiology 7(2): 218-221.

2. Borg G, Linderholm H (1967) Perceived exertion and pulse rate during graded exercise in various age groups. Journal of Internal Medicine 181(S472): 194-206.

3. Qadir MI, Javid A (2018) Awareness about Crohn's Disease in biotechnology students. Glo Adv Res J Med Medical Sci 7(3): 62-64.

4. Qadir MI, Saleem A (2018) Awareness about ischemic heart disease in university biotechnology students. Glo Adv Res J Med Medical Sci 7(3): 59-61.

5. Qadir MI, Ishfaq S (2018) Awareness about hypertension in biology students. Int J Mod Pharma Res 7(2): 08-10.

6. Qadir MI, Mehwish (2018) Awareness about psoriasis disease. Int J Mod Pharma Res 7(2): 17-18.

7. Qadir MI, Shahzad R (2018) Awareness about obesity in postgraduate students of biotechnology. Int J Mod Pharma Res 7(2): 14-16.

8. Qadir MI, Rizvi M (2018) Awareness about thalassemia in post graduate students. MOJ Lymphology \& Phlebology 2(1): 14-16.

9. Qadir MI, Ghalia BA (2018) Awareness survey about colorectal cancer in students of M. Phil Biotechnology at Bahauddin Zakariya University, Multan, Pakistan. Nov Appro in Can Study, 1(3): NACS.000514.2018.

10. Qadir MI, Saba G (2018) Awareness about intestinal cancer in university student. Nov Appro in Can Study 1(3): NACS.000515.2018.

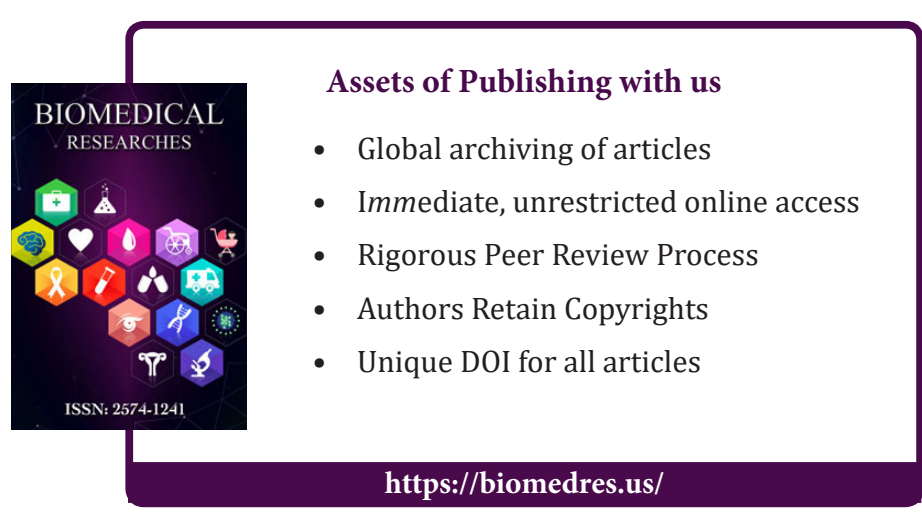

Copyright@ Tooba Komal| Biomed J Sci \& Tech Res| BJSTR. MS.ID.002583. 